\title{
On-campus food environment, purchase behaviours, preferences and opinions in a Norwegian university community
}

\author{
Naiara Martinez-Perez ${ }^{1}$, Liv Elin Torheim ${ }^{2}$, Nerea Castro-Díaz ${ }^{3}$ and \\ Marta Arroyo-lzaga ${ }^{3, *}$ \\ 'Department of Nursing, Faculty of Medicine and Nursing, University of the Basque Country UPV/EHU, Leioa, Spain: \\ ${ }^{2}$ Department of Nursing and Health Promotion, Faculty of Health Sciences, OsloMet - Oslo Metropolitan University, \\ Oslo, Norway: ${ }^{3}$ Department of Pharmacy and Food Sciences, Faculty of Pharmacy, University of the Basque Country \\ UPV/EHU, Paseo de la Universidad, 7, 01006 Vitoria-Gasteiz, Spain
}

Submitted 8 January 2021: Final revision received 12 May 2021: Accepted 18 June 2021: First published online 25 June 2021

\begin{abstract}
Objective: To assess the food environment at OsloMet, through the nutritional profile and processing level of available commercial foods and drinks, as well as to determine food-purchasing behaviours, preferences and opinions on the food environment, in order to identify whether interventions on campus need to be conducted.

Design: Cross-sectional descriptive study.

Setting: Pilestredet and Kjeller campus of OsloMet (Norway).

Participants: To analyse the nutritional profile of products offered at all food outlets (seven canteens, three coffee shops and two vending machines) at the main campuses three criteria were applied: those proposed by the Spanish Agency for Food Safety and Nutrition, the UK nutrient profiling model and those of the Food and Drink Industry Professional Practices Committee Norway. In addition, products were classified by processing level, using the NOVA system. Food purchasing, food choice behaviours and opinions were analysed through a survey online, in which 129 subjects participated.

Results: With regard to the first of the objectives, the combination of the abovementioned criteria showed that $39.8 \%$ of the products were 'unhealthy' and $85.9 \%$ were 'ultra-processed'. Regarding the second objective, the most important determinants of food choice were taste, convenience, and cost and nutrition/health value. The most common improvements suggested were lowering the cost, improving the allergen information on labelling and increasing the variety of fresh and healthy foods.

Conclusions: A high proportion of the products offered were considered 'unhealthy' and highly processed. Interventions that improve food prices, availability and information on labelling would be well-received in this community.
\end{abstract}

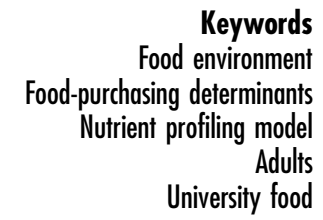

Keywords

asing determinants University food
Food environment has been defined as 'the interface that mediates one's food acquisition and consumption within the wider food system ${ }^{\prime(1)}$. There is a growing evidence from diverse settings regarding the influence of availability and accessibility of healthy or unhealthy food on individual obesity risk ${ }^{(2)}$. For example, improved access to supermarkets which mainly provide fresh foods was associated with increased fruit and vegetable intake ${ }^{(3)}$ and reduced levels of overweight/obesity ${ }^{(4)}$. Concurrently, improved access to fast-food restaurants was associated with an increased prevalence of overweight/obesity ${ }^{(5)}$. Although some other studies have reported null or counter-intuitive findings about the health impact of the local food environment ${ }^{(6,7)}$, the influence of the food environment on eating behaviour seems to be evident, as has been found in many studies carried out in several scenarios, including schools ${ }^{(8)}$ and universities $^{(9,10)}$.

In university settings, students and staff typically spend a substantial amount of time at the institution, as much as 5-30 h a week, or even more, over many years. Therefore, these institutions have a strong responsibility to provide a food environment that enables those who study or work and live in them to make healthier food choices $^{(11)}$. Organisational food environments, as those

*Corresponding author: Email marta.arroyo@ehu.eus

(C) The Author(s), 2021. Published by Cambridge University Press on behalf of The Nutrition Society. This is an Open Access article, distributed under the terms of the Creative Commons Attribution-NonCommercial-NoDerivatives licence (http://creativecommons.org/licenses/by-nc-nd/4.0/), which permits non-commercial re-use, distribution, and reproduction in any medium, provided the original work is unaltered and is properly cited. The written permission of Cambridge University Press must be obtained for commercial re-use or in order to create a derivative work. 
found in universities, among others, constitute a strategic setting for promoting a healthy diet, since it has a strong influence on the dietary behaviours of the individuals frequenting this environment ${ }^{(12)}$. The university campus warrants a special attention given that, while at the university, the students acquire eating habits that can persist into adult life, thereby representing a unique opportunity for promoting a healthy diet ${ }^{(13)}$. Additionally, the period of university studies is a high-risk period for weight gain ${ }^{(14,15)}$. Some studies observed that first-year university students have significant weight gain ${ }^{(16)}$, followed by an ongoing slow but steady increase in weight ${ }^{(17)}$.

Recent studies have found associations between overweight/obesity both among university students ${ }^{(18,19)}$ and staff and unhealthy eating behaviours ${ }^{(20)}$. Additionally, university employees with overweight/obesity were more influenced by food choices available in on-campus dining facilities than those with normal weight ${ }^{(20)}$. In this regard, previous research indicates that many campus food environments are potentially obesogenic, due to the frequent supply and promotion of energy-dense, nutrient-poor foods ${ }^{(21)}$.

To our knowledge, there are no studies on this topic in Norwegian universities; thus, the present study had a double objective. On the one hand, it aimed to assess the food environment at the main university campuses at OsloMet - Oslo Metropolitan University, through the nutritional profile and processing level of available commercial foods and drinks. On the other hand, it aimed to determine food-purchasing behaviours, preferences and opinions about the food environment among students and staff. This study will give an in-depth understanding of the nature of an organisational food environment to which younger students and working adults are exposed. Furthermore, the findings will inform the need for modification of the food environment and give inputs to design effective interventions to improve the food environment in this and similar universities.

\section{Methods}

\section{Study design and setting}

A cross-sectional observational study was conducted which assessed food and drinks available, as well as students' and staff's food purchasing, food choice behaviours and opinions of the campus food environment across the main campuses, in terms of students and staff numbers (Pilestredet and Kjeller campus), of OsloMet - Oslo Metropolitan University (Oslo, Norway). Pilestredet and Kjeller campus had 19500 students and 2200 staff in the academic year 2019-2020, whereas the campus excluded in the present study, Sandvika campus, was about 500 students and only one employee ${ }^{(22)}$.

\section{Food environment observation}

The researchers assessed the availability of commercial foods and drinks at all food outlets within two of the three campuses, that is, of a total of twelve food outlets (seven canteens, three coffee shops and two vending machines). The distribution of food outlets by campus was as follows: eight at Pilestredet campus (six canteens and two coffee shops) and four at Kjeller campus (one canteen, one coffee shop and two vending machines, one vending machine for hot drinks and one for snacks).

The food outlets within Pilestredet and Kjeller campus were identified, thanks to the information provided by the Foundation for Student Life in Oslo and Akershus (Studentsamskipnaden i Oslo og Akershus ( $\mathrm{SiO}$ )). $\mathrm{SiO}$ is a student welfare organisation that operates food services on campus at universities in Oslo and Akershus (Norway). The food and drinks list was also obtained through SiO. They provided the following information: product description (including flavour or ingredient variations, such as barbecue potato chips), brand and portion weight. Subsequently, the products were categorised using the classification shown in the online supplementary material, Supplemental Table 1. It should be noted that this list did not include hot drinks such as coffee or chocolate.

The nutritional information was obtained from different sources, as follows (according to the order of preference): nutrition labelling, manufacturer's website and/or Kostholdsplanleggeren, a diet tool from the Norwegian Directorate of Health and the Norwegian Food Safety Authority ${ }^{(23)}$. For each product, the energy content and the following nutrients were estimated: protein, total fat, trans-fatty acids, SFA, sugar and $\mathrm{Na}$, as well as the salt content. These data were calculated per $100 \mathrm{~g}$ of product and per portion.

To indicate the healthiness of each food or drink item, we used three nutrient profiling models (NPM) based on different construct and criterion: those proposed by the Spanish Agency for Food Safety and Nutrition (Agencia Española de Seguridad Alimentaria y Nutrición AECOSAN) ${ }^{(24)}$, the United Kingdom $\mathrm{NPM}^{(25)}$ and those of the Food and Drink Industry Professional Practices Committee Norway (Matbransjens Faglige Utvalg (MFU)) ${ }^{(26)}$.

The former criteria are those designed for the food supply present in vending machines, canteens and kiosks in education centres. We selected the AECOSAN criteria because the same criteria have been applied previously in previous studies involving staff and university students (Martinez-Perez N, Arroyo-Izaga M. Food products available in vending machines on campus: nutritional profile, processing level, promotion and price. In review unpublished results), which allows us to establish comparisons with these data sets.

The AECOSAN criteria have six components: energy, total fat, SFA, trans-fatty acids, sugar and salt. These criteria set the following limits per $100 \mathrm{~g}$ of product: $\leq 400 \mathrm{kcal}$, $\leq 15.6 \mathrm{~g}$ total fat, $\leq 4.4 \mathrm{~g}$ SFA, $\leq 1 \mathrm{~g}$ trans-fatty acids, $\leq 30 \mathrm{~g}$ sugar and $\leq 1 \mathrm{~g}$ salt. Products that did not meet at least one of the cut-offs were considered 'unhealthy'. These criteria focus on energy density and nutrients that 
have the potential to negatively impact on health or 'at-risk' nutrients, which can be a limitation when analysing the nutrient profiling. For this reason, we also used the United Kingdom $\mathrm{NPM}^{(27)}$, which was developed by the UK Food Standards Agency ${ }^{(27)}$. This instrument is one of the most frequently validated models ${ }^{(28)}$.

In addition to the 'at-risk' nutrients, the UK NPM also includes foods and nutrients considered to have a beneficial effect on health (i.e. fruit, vegetables, nuts, protein and fibre). The UK NPM uses a simple scoring system wherein points are allocated on the basis of the nutrient content of $100 \mathrm{~g}$ of food or drink. To do this, the nutrient content of each food and drink was assessed against a set of published criteria to determine whether it contains certain nutrients above or below particular thresholds. This model has seven components: energy, SFA, sugar, $\mathrm{Na}$, 'fruit, vegetables and nuts', fibre and protein, and provides a single score for any given food/drink product, based on calculating the number of points for 'negative' nutrients that can be offset by points for 'positive' nutrients.

Points are awarded for energy, SFA, sugar and $\mathrm{Na}$ ('A' nutrients) and fruit, vegetable and nut content, fibre and protein (' $\mathrm{C}$ ' foods or nutrients). In the 'A' category, a maximum of ten points can be awarded for each component and in the ' $\mathrm{C}$ ' category, a maximum of five points. The score for ' $\mathrm{C}$ ' foods or nutrients is subtracted from the 'A' nutrients' score to give a final score. If the score is $<4$ for foods or $<1$ for drinks, the product is classified as 'healthy'. When scores exceed these limits, however, the product is classified as 'unhealthy' (e.g. high-saturated fat, sugar and/or salt content). Nonetheless, this model also has limitations, since certain foods with high levels of a particular 'at-risk' nutrient (e.g. fat), which are also key sources of some micronutrients, may be classified as 'unhealthy'. For example, some cheeses may be classified as 'unhealthy', despite being key sources of dietary $\mathrm{Ca}$ and riboflavin. To overcome this limitation, we added other criteria in the evaluation of the nutrient profiling, those that are commonly used to regulate marketing of unhealthy foods and drinks to children in Norway, which is a self-regulation scheme operated by the industry through their organisation Food and Drink Industry Professional Practices Committee Norway (MFU) ${ }^{(26)}$.

The MFU provides a list of 'unhealthy' products according to their content in one or more of the following components, in most cases per $100 \mathrm{~g}$ of product: total fat, SFA, sugar, salt, nutritional density and energy density. The limits established for each of these components vary according to the type of food. An example is that milk products with more than $15 \mathrm{~g}$ added sugar per litre, breakfast cereals with more than $20 \mathrm{~g}$ sugar in total per $100 \mathrm{~g}$ and yogurt with more than $11 \mathrm{~g}$ sugar in total per $100 \mathrm{~g}$ are classified as 'unhealthy' according to this criteria.

Finally, the resulting categories after applying the above-mentioned three criteria, AECOSAN, UK NPM and MFU, were combined as follows: if a product had been classified as 'unhealthy' according to at least one of the classifications, it was considered 'unhealthy'. The rest of the products were categorised as 'healthy'. In addition, the food or drink items were classified using the NOVA system, which categorises foods according to their nature, purpose and degree of industrial processing ${ }^{(29)}$. This system distinguishes between the following groups: (i) unprocessed or minimally processed foods, (ii) processed culinary ingredients, (iii) processed foods and (iv) ultra-processed products ${ }^{(30)}$. In the present study, the category 'processed culinary ingredients' was not assessed because this type of product was a minority within the food-outlets studied.

\section{Survey on food purchasing, food choice behaviours and opinions}

Data were registered using an adapted version of the questionnaire used by Tam et al. ${ }^{(11)}$. First, the original version was adapted to be used in another public university, the University of the Basque Country (UPV/EHU) (in northern Spain) (Martinez-Perez N, Telleria-Aramburu N, Insúa P, Hernández I, Telletxea S, Ansotegui L, Rebato E, Basabe N, Mtz. de Pancorbo M, Rocandio AM, Arroyo-Izaga M. On-campus food environment, purchase behaviours, preferences and opinions in a Spanish university community. In review - unpublished results). This adapted version of the questionnaire was translated using the double translation technique and piloted (including a previous phase of debriefing and piloting in ten students, ten teaching staff and ten administrative staff). Second, the English translation of the adapted and piloted version was contrasted with the original version. Third, this version was reviewed by five academic staff of OsloMet, to ensure that questions were easily understood, free from bias and appropriately structured. The feedback was used to design the final survey instrument we applied in this study.

The final adapted version was divided into four sections with thirty-six questions: demographic characteristics, food-purchasing behaviours, determinants, and consumptions and opinions about the current campus food environment. Demographic items included age (in categories), sex, association with which faculty, hours spent on campus, and, in the case of students, study status (full-time or part-time) and degree level (undergraduate or postgraduate studies). Food-purchasing behaviour questions ascertained motives for and frequency of purchasing different types of foods and drinks.

Opinion items regarding the food environment employed a 5-point Likert scale (strongly agree, agree, neutral, disagree or strongly disagree) to determine views on the current and potential opportunity to change aspects of the food environment and a 0-10 scale (not at all satisfied to extremely satisfied) to determine the satisfaction levels with the provision of foods and beverages on campus. Most questions were closed-ended ( $n$ 35), but 
the respondents had the opportunity to provide openended suggestions ( $n$ 2) regarding improvements to the campus food environment. The category analysis of the open-ended questions was undertaken by two of the researchers (N.M.-P. and M.A.-I.) independently and then conjointly. This analysis was conducted by means of text analysis procedures ${ }^{(31)}$. Themes of participant responses were developed through cascading analysis of responses, rather than through an a priori construct. In several steps, the researchers iteratively reviewed answers and generated thematic categories. After the final coding was completed, the categories were combined into major themes. There were no discrepancies between the categories derived by the two investigators, and none of these categories differed from the opinion items formulated as closed-ended questions. Therefore, these open-ended answers were incorporated into closed-ended ones in the category 'agree' of the corresponding item. In particular, the opinion items formulated as closed-ended questions and the number of open-ended responses that have been incorporated into each of them were the following: 'variety of food/ beverages' ( $n$ 6), 'higher quality foods' ( $n$ 2), 'detailed nutritional information of foods or dishes' ( $n$ 1) and 'healthier foods for lower cost' ( $n$ 1).

Nine questions from the original questionnaire were excluded (questions number 8, 17, 30, 35 and 26-30) to adapt it to the characteristics of the environment in which the research was carried out. In addition, the questions about food consumption were adapted with respect to the original questionnaire. Thus, items that were commonly consumed in the current food environment (e.g. menu starter, main course and desserts) replaced certain products that were not commonly consumed (e.g. hot ethnic cuisine, casserole/stew/roast/BBQ food/schnitzel and sushi). Before the survey was implemented, the questionnaire was tested by academic staff within the university to ensure that questions were easily understood, free from bias and appropriately structured. Feedback was used to design the final survey instrument.

The survey was self-administered and completed online using the application Nettskjema (University Information Technology Centre, University of Oslo, Oslo, Norway) over 12 weeks between March and May 2020. The survey was advertised on participating campuses using electronic newsletters and the university Facebook page. All enrolled students and current staff were eligible to participate. Participants could complete the survey only if they consented to participate in this study on the first page. Participation was anonymous, but to encourage completion, a gift card prize-draw incentive was used. To ensure respondents were current staff and students, only university emails were considered in the draw. Survey responses were separated from the lucky draw entry to maintain anonymity.

The sample was drawn according to the data on the number of students and staff enrolled or employed at
Pilestredet and Kjeller campus in 2019 that was 21700 (2200 staff and 19500 students) ${ }^{(22)}$. Regarding the distribution of this campus community by sex, the percentage of women was around $68 \%$ ( $68 \%$ of students and $66 \%$ of staff were women); by area of knowledge, the percentage of Health Sciences was about 23\% (22\% of students and $33 \%$ of staff were from Health Sciences) ${ }^{(22)}$. Taking into account the total population ( $n 21$ 700), the sample size was estimated to be a minimum of ninety-six participants based on the precision level of $+/-10 \%$, the CI of $95 \%$ and $P=0.05$, using the Epidat 3.0 program $^{(32)}$. Finally, 129 subjects (seventy-one students and fifty-eight staff) participated in the study.

\section{Statistical analysis}

The data were analysed using IBM SPSS Statistics for Windows, version 22.0 (IBM Corp.). The results are expressed as means (SD) for continuous variables and as percentages for categorical variables. The differences were analysed using the $\chi^{2}$ test or the Fisher exact test. The $\kappa$ coefficient was calculated to investigate the degree of agreement between the three NPM (AECOSAN, UK NPM and MFU) and between these models and NOVA classification. The $\kappa$ results were interpreted as follows: values $\leq 0$ no agreement, $0 \cdot 1-0 \cdot 20$ none to slight, 0.21-0.40 fair, 0.41-0.60 moderate, 0.61-0.80 substantial and 0.81-1.00 almost perfect ${ }^{(33)}$. All tests were two-sided, and $P$-values $<0.05$ were considered statistically significant.

\section{Results}

\section{Food environment observation}

A total of 256 foods/drinks were surveyed at Pilestredet and Kjeller campus of OsloMet. As shown in Table 1, the most common food/drink options were sweet snacks (58.5\% of the solid foods and $39 \cdot 1 \%$ of the total products) and sugarsweetened carbonated drinks $(23.5 \%$ of the total drinks and $7.8 \%$ of the total products). Approximately half of the foods and drinks did not meet the AECOSAN's criteria $(52.3 \%)$ and the UK NPM's criteria (46.9\%). Moreover, almost two-thirds (73.4\%) did not meet the MFU's criteria. The AECOSAN's criterion that was most frequently unfulfilled was the SFA quantity in foods and the sugar content in drinks. The combination of the above-mentioned three criteria, AECOSAN, UK NPM and MFU, showed that 39.8\% of the products were classified as 'unhealthy'. Moreover, according to the NOVA system, most of the products offered were categorised as 'ultra-processed', specifically $87.7 \%$ of the foods and $82.4 \%$ of drinks.

Comparison of the results obtained from the three NPM showed a substantial agreement between UK NPM and AECOSAN, a fair-moderate agreement between UK NPM and MFU, and a slight-fair agreement between AECOSAN and MFU (online supplementary material, Supplemental 
Table 1 Nutritional profile and processing level of commercial products sold on Pilestredet and Kjeller campus of OsloMet

\begin{tabular}{|c|c|c|c|c|c|c|c|c|c|c|c|c|}
\hline \multirow[b]{3}{*}{ Type of product } & \multirow[b]{3}{*}{$n$} & \multirow[b]{3}{*}{$\%$} & \multicolumn{10}{|c|}{ Unfulfillment of } \\
\hline & & & \multicolumn{7}{|c|}{ AECOSAN's criteria* $, \dagger, \%$} & \multirow[b]{2}{*}{$\begin{array}{l}\text { UK NPM's } \\
\text { criteriall, \% }\end{array}$} & \multirow[b]{2}{*}{$\begin{array}{l}\text { MFU's } \\
\text { criteriaף }\end{array}$} & \multirow{2}{*}{$\begin{array}{c}\begin{array}{c}\text { NOVA } \\
\text { system }\end{array}{ }^{\star *}, \% \\
\begin{array}{c}\text { Ultra- } \\
\text { processed }\end{array}\end{array}$} \\
\hline & & & Totalł & Energy§ & $\begin{array}{l}\text { Total } \\
\text { fat§}\end{array}$ & SFA§ & TFA§ & Sugar§ & Salt§ & & & \\
\hline \multicolumn{13}{|l|}{ Solid foods } \\
\hline Fruits & 8 & $3 \cdot 1$ & $50 \cdot 0$ & - & - & - & - & $100 \cdot 0$ & - & 37.5 & 37.5 & 37.5 \\
\hline Nuts & 6 & $2 \cdot 3$ & $83 \cdot 3$ & $100 \cdot 0$ & $100 \cdot 0$ & $100 \cdot 0$ & - & - & - & - & 83.3 & $50 \cdot 0$ \\
\hline Salty snacks & 19 & 7.4 & 68.4 & 7.7 & $30 \cdot 8$ & $30 \cdot 8$ & - & $100 \cdot 0$ & 76.9 & 21.1 & $36 \cdot 8$ & 84.2 \\
\hline Sandwiches & 3 & $1 \cdot 2$ & $100 \cdot 0$ & $100 \cdot 0$ & $100 \cdot 0$ & $100 \cdot 0$ & - & - & $100 \cdot 0$ & $100 \cdot 0$ & $100 \cdot 0$ & $100 \cdot 0$ \\
\hline Sweet snacks & 84 & $32 \cdot 8$ & 79.6 & $52 \cdot 2$ & 80.6 & $82 \cdot 1$ & - & 44.8 & 1.5 & $82 \cdot 1$ & 96.4 & 94.0 \\
\hline Yogurts & 17 & $6 \cdot 6$ & - & - & - & - & - & - & - & 5.9 & 52.9 & $88 \cdot 2$ \\
\hline $\begin{array}{l}\text { Other dairy snacks } \\
\text { (porridge, pudding, etc.) } \\
\text { Others }\end{array}$ & 16 & $6 \cdot 2$ & - & - & - & - & - & - & - & $16 \cdot 7$ & $100 \cdot 0$ & $83 \cdot 3$ \\
\hline w. added sugars & 11 & 4.3 & $90 \cdot 9$ & $70 \cdot 0$ & - & $60 \cdot 0$ & - & $100 \cdot 0$ & $10 \cdot 0$ & 90.9 & $100 \cdot 0$ & $100 \cdot 0$ \\
\hline w. sweeteners & 5 & 1.9 & $40 \cdot 0$ & - & - & - & - & - & $100 \cdot 0$ & $40 \cdot 0$ & $100 \cdot 0$ & $100 \cdot 0$ \\
\hline Total solid foods & 171 & $66 \cdot 8$ & $60 \cdot 8$ & $49 \cdot 0$ & 63.5 & $70 \cdot 2$ & - & $42 \cdot 3$ & $16 \cdot 3$ & $55 \cdot 6$ & 81.9 & $87 \cdot 7$ \\
\hline \multicolumn{13}{|l|}{ Drinks } \\
\hline \multicolumn{12}{|l|}{ Carbonated drinks } & - \\
\hline Soda & 2 & 0.8 & - & - & - & - & - & - & - & - & - & - \\
\hline w. added sugars & 20 & $7 \cdot 8$ & $85 \cdot 0$ & - & - & - & - & $100 \cdot 0$ & - & $90 \cdot 0$ & $100 \cdot 0$ & $100 \cdot 0$ \\
\hline w. sweeteners & 17 & $6 \cdot 6$ & - & - & - & - & - & - & - & - & $100 \cdot 0$ & $100 \cdot 0$ \\
\hline $\begin{array}{l}\text { w. added sugars } \\
\text { and sweeteners }\end{array}$ & 1 & 0.4 & - & - & - & - & - & - & - & $100 \cdot 0$ & $100 \cdot 0$ & $100 \cdot 0$ \\
\hline \multicolumn{13}{|l|}{ Non-carbonated drinks } \\
\hline w. added sugars & 9 & 3.5 & - & - & - & - & - & - & - & $11 \cdot 1$ & $100 \cdot 0$ & $100 \cdot 0$ \\
\hline w. sweeteners & 1 & 0.4 & - & - & - & - & - & - & - & - & $100 \cdot 0$ & $100 \cdot 0$ \\
\hline Fruit juices & 11 & $4 \cdot 3$ & $9 \cdot 1$ & - & - & - & - & $100 \cdot 0$ & - & $9 \cdot 1$ & - & $27 \cdot 3$ \\
\hline Milk & 2 & 0.8 & - & _- & - & - & _- & - & - & - & - & - \\
\hline Dairy drinks & 1 & 0.4 & $66 \cdot 7$ & - & - & 8.3 & - & $75 \cdot 0$ & $50 \cdot 0$ & $22 \cdot 2$ & - & $100 \cdot 0$ \\
\hline Vegetable drinks & 1 & 0.4 & - & - & - & - & - & - & - & 100.0 & - & $100 \cdot 0$ \\
\hline Total drinks & 85 & 33.2 & $35 \cdot 3$ & - & - & 3.3 & - & $90 \cdot 0$ & $20 \cdot 0$ & 29.4 & $56 \cdot 5$ & 82.4 \\
\hline Total & 256 & & $52 \cdot 3$ & $38 \cdot 1$ & $49 \cdot 3$ & $55 \cdot 2$ & - & 53.0 & $17 \cdot 2$ & $46 \cdot 9$ & 73.4 & $85 \cdot 9$ \\
\hline
\end{tabular}

NPM, nutrient profiling model; TFA, trans-fatty acids.

${ }^{*}$ AECOSAN, 2010(24).

†The same product may not meet more than one criterion, and therefore, the sum of the criteria does not result in the total percentage of products that do not fulfil AECOSAN's criteria.

¥The product that did not meet at least one of the criterion was considered 'unhealthy'.

$\S$ The percentage of products that did not meet each criterion among those considered 'unhealthy' is shown.

IIDepartment of Health, 2011(25).

IMFU, 2013(26).

**Monteiro et al., 2016(29).

Table 2). Regarding the comparison between the NPM and processing level classification, a slight-fair agreement was observed between the NOVA system and each of the NPM, separately and also combined (see online supplementary material, Supplemental Table 3).

\section{General characteristics of participants in the survey on food purchasing, food choice behaviours and opinions}

Demographic characteristics of the participants in the survey on food purchasing, food choice behaviours and opinions are presented in Table 2 . The majority of the participants were women (82.2\%), enrolled full-time (90.7\%) and were mostly from non-Health Sciences (58.9\%), with no differences between students and staff for these variables. The percentages of women and subjects from Health Sciences area were higher in the study sample than in the total population, that is, in the campus community (women, $82.2 \%$ v. $68 \%$ in the campus community, $P<0.001$; Health Sciences, $41 \%$ v. $23 \%, P<0.001)$. As for age, most students (52.1\%) were 25-44 years, whereas most employees (60.3\%) were over 45 years. Among students, 38.0\% were undergraduates and $17.1 \%$ postgraduates. Moreover, $32.6 \%$ of the participants reported following a special diet, this percentage was higher for students than employees $(P<0.05)$. Vegetarian or vegan diets were the diets most adhered to by the participants, followed by weight-management diets.

\section{Food purchasing and food choice behaviours}

A majority of the respondents (92.2\%) had purchased foods and/or drinks from an OsloMet campus in the last month. Among the participants, 54.3\% reported buying foods or drinks on at least $50 \%$ of the occasions they were 
Table 2 General characteristics of participants of Pilestredet and Kjeller campus of OsloMet in the survey on food purchasing, food choice behaviours and opinions

\begin{tabular}{|c|c|c|c|c|c|c|c|}
\hline \multirow[b]{2}{*}{ Variables } & \multicolumn{2}{|c|}{ Total ( $n$ 129) } & \multicolumn{2}{|c|}{ Students $(n 71)$} & \multicolumn{2}{|c|}{ Staff $(n 58)$} & \multirow[b]{2}{*}{$P$} \\
\hline & $n$ & $\%$ & $n$ & $\%$ & $n$ & $\%$ & \\
\hline \multicolumn{8}{|l|}{ Age } \\
\hline$<25$ years & 30 & $23 \cdot 3$ & 30 & $42 \cdot 3$ & - & & \\
\hline $25-44$ years & 60 & $46 \cdot 5$ & 37 & $52 \cdot 1$ & 23 & 39.7 & \\
\hline$\geq 45$ years & 39 & $30 \cdot 2$ & 4 & $5 \cdot 6$ & 35 & $60 \cdot 3$ & $<0.001$ \\
\hline \multicolumn{8}{|l|}{ Area of knowledge } \\
\hline Health sciences & 53 & $41 \cdot 1$ & 30 & $42 \cdot 3$ & 23 & 39.7 & \\
\hline Non-health sciences & 76 & 58.9 & 41 & $57 \cdot 7$ & 35 & $60 \cdot 3$ & 0.765 \\
\hline \multicolumn{8}{|l|}{ Study or work contract } \\
\hline Full-time & 117 & 90.7 & 65 & 91.5 & 52 & 89.7 & \\
\hline Part-time & 12 & $9 \cdot 3$ & 6 & 8.5 & 6 & $10 \cdot 3$ & 0.713 \\
\hline \multicolumn{8}{|l|}{ Special diet* } \\
\hline Vegetarian/vegan & 20 & $15 \cdot 5$ & 12 & $16 \cdot 9$ & 8 & $13 \cdot 8$ & \\
\hline Therapeutic & 11 & 8.5 & 8 & 11.3 & 3 & $5 \cdot 2$ & \\
\hline Weight-management & 16 & $12 \cdot 4$ & 7 & 9.9 & 9 & $15 \cdot \overline{5}$ & \\
\hline Religious motives & 4 & $3 \cdot 1$ & 3 & $4 \cdot 2$ & 1 & 1.7 & 0.495 \\
\hline
\end{tabular}

*Multiple answer.

Significant $P$-values are highlighted in bold.

Table 3 Occasions of foods and drinks purchase from a university outlet of OsloMet

\begin{tabular}{|c|c|c|c|c|c|c|c|}
\hline \multirow[b]{2}{*}{ Eating/drinking occasion* } & \multicolumn{2}{|c|}{ Total $n 129$} & \multicolumn{2}{|c|}{ Students $n 71$} & \multicolumn{2}{|c|}{ Staff $n 58$} & \multirow[b]{2}{*}{$P$} \\
\hline & $n$ & $\%$ & $n$ & $\%$ & $n$ & $\%$ & \\
\hline \multicolumn{8}{|l|}{ Foods } \\
\hline Breakfast & 23 & $17 \cdot 8$ & 22 & 31.0 & 1 & 1.7 & $<0.001$ \\
\hline Lunch & 117 & $90 \cdot 7$ & 63 & 88.7 & 54 & 93.1 & 0.395 \\
\hline Dinner & 28 & $21 \cdot 7$ & 22 & $31 \cdot 0$ & 6 & $10 \cdot 3$ & 0.005 \\
\hline Snack & 38 & 29.5 & 30 & $42 \cdot 3$ & 8 & $13 \cdot 8$ & $<0.001$ \\
\hline \multicolumn{8}{|l|}{ Beverages } \\
\hline Breakfast & 40 & $31 \cdot 0$ & 30 & $42 \cdot 3$ & 10 & $17 \cdot 2$ & 0.002 \\
\hline Lunch & 55 & $42 \cdot 6$ & 41 & $57 \cdot 7$ & 14 & $24 \cdot 1$ & $<0.001$ \\
\hline Dinner & 13 & $10 \cdot 1$ & 11 & $15 \cdot 5$ & 2 & 3.6 & 0.024 \\
\hline Snack & 45 & 34.9 & 31 & $43 \cdot 7$ & 14 & $24 \cdot 1$ & 0.021 \\
\hline
\end{tabular}

*Multiple answer.

Significant $P$-values are highlighted in bold.

on campus. One-third of the participants (32.6\%) reported spending between 100 and 200 NOK on foods/drinks on campus during an average week. These purchases were mainly done in the canteen of the campus $(72.9 \%)$, followed by the coffee shops (26.4\%) and other (i.e. vending machines) ( $0.8 \%)$. No significant differences between students and staff were observed in these five four variables: foods and/or drinks purchasing in the last month, frequency of purchasing, weekly spending on purchasing (this variable was dichotomised as ' $\geq 200$ NOK' and ' $<200$ NOK') and purchase place. Both foods and drinks were commonly purchased at lunch and between meals (Table 3). The purchase occasions were higher among students than staff $(P<0.05)$, with the exception of food purchase for lunch that was similar in both groups $(P>0.05)$.

Table 4 shows the purchase of foods (categorised as hot and cold foods and snacks) and drinks with a frequency of once a week or higher. Cold foods (87.6\%) and drinks
(77.5\%) were the most purchased items, followed by hot foods (49.7\%) and snacks (40.3\%). In each category, products most consumed were salads and hot drinks, such as coffee or hot chocolate, followed by cold sandwiches or wraps. More students than staff consumed cold sandwiches or wraps, fresh fruits, other snacks and drinks in general $(P<0.05)$.

Food-purchasing determinants are summarised in Table 5. Taste was the most important determinant for the respondents. Availability, cost and nutritional value were also considered as main factors when buying food on campus. No differences were found between students and employees for most purchasing determinants, with the exception of sensory appeal such as smell and look, and health. These aspects were more important for staff than for students $(P<0.05)$. In addition, $39.5 \%$ of participants affirmed that ' $2 \times 1$ offers' or 'offers of large portions of food prepared at reduced prices' influence their 
Table 4 Purchase of foods and drinks with a frequency of once weekly or higher from a university outlet of OsloMet

\begin{tabular}{|c|c|c|c|c|c|c|c|}
\hline \multirow[b]{2}{*}{ Variables* } & \multicolumn{2}{|c|}{ Total $n 129$} & \multicolumn{2}{|c|}{ Students $n 71$} & \multicolumn{2}{|c|}{ Staff $n 58$} & \multirow[b]{2}{*}{$P$} \\
\hline & $n$ & $\%$ & $n$ & $\%$ & $n$ & $\%$ & \\
\hline \multicolumn{8}{|l|}{ Hot food } \\
\hline Hot sandwiches, wraps, pizzas and burgers & 10 & $7 \cdot 8$ & 9 & $12 \cdot 7$ & 1 & 1.7 & 0.023 \\
\hline Menu & 24 & $18 \cdot 6$ & 13 & $18 \cdot 3$ & 11 & $19 \cdot 0$ & 0.924 \\
\hline Others hot foods $†$ & 30 & $23 \cdot 3$ & 17 & 23.9 & 13 & $22 \cdot 4$ & 0.235 \\
\hline \multicolumn{8}{|l|}{ Cold food } \\
\hline Cold sandwiches or wraps & 28 & $21 \cdot 7$ & 22 & $31 \cdot 0$ & 6 & $10 \cdot 3$ & 0.005 \\
\hline Salads & 76 & $58 \cdot 9$ & 40 & $56 \cdot 3$ & 36 & $62 \cdot 1$ & 0.510 \\
\hline Others cold foods $\ddagger$ & 9 & $7 \cdot 0$ & 7 & 9.9 & 2 & 3.4 & 0.185 \\
\hline \multicolumn{8}{|l|}{ Snacks } \\
\hline Sweet snacks & 15 & $11 \cdot 6$ & 9 & $12 \cdot 7$ & 6 & $10 \cdot 3$ & 0.681 \\
\hline Fresh fruit & 21 & $16 \cdot 3$ & 17 & 23.9 & 4 & 6.9 & 0.009 \\
\hline Others snacks§ & 16 & $12 \cdot 4$ & 13 & $18 \cdot 3$ & 3 & $5 \cdot 2$ & 0.024 \\
\hline \multicolumn{8}{|l|}{ Drinks } \\
\hline Coffee, tea, hot chocolate, etc. & 54 & 41.9 & 38 & 53.5 & 16 & $27 \cdot 6$ & 0.003 \\
\hline Soft drinks, energy drinks, flavoured drinks, etc. & 19 & $14 \cdot 7$ & 17 & 23.9 & 2 & 3.4 & 0.001 \\
\hline Other drinks\| & 27 & $20 \cdot 9$ & 26 & $36 \cdot 6$ & 1 & $1 \cdot 7$ & $<0.001$ \\
\hline
\end{tabular}

*Multiple answer.

†'Others hot foods' = soup, main course, starter, dairy products

\#'Others cold foods' = dairy products, main course.

$\S$ 'Other snacks' $=$ non-specified on the survey.

Il'Other drinks' = iced coffee.

Significant $P$-values are highlighted in bold.

Table 5 Foods and drinks from a university outlet of OsloMet purchasing determinants

\begin{tabular}{|c|c|c|c|c|c|c|c|}
\hline \multirow[b]{2}{*}{ Variables* } & \multicolumn{2}{|c|}{ Total $n 129$} & \multicolumn{2}{|c|}{ Students $n 71$} & \multicolumn{2}{|c|}{ Staff $n 58$} & \multirow[b]{2}{*}{$P$} \\
\hline & $n$ & $\%$ & $n$ & $\%$ & $n$ & $\%$ & \\
\hline \multicolumn{8}{|l|}{ Sensory appeal } \\
\hline Tastes good & 129 & $100 \cdot 0$ & 71 & $100 \cdot 0$ & 58 & $100 \cdot 0$ & - \\
\hline Smells nice & 106 & $82 \cdot 2$ & 54 & $76 \cdot 1$ & 52 & 89.7 & 0.045 \\
\hline Looks nice & 91 & $70 \cdot 5$ & 44 & $62 \cdot 0$ & 47 & $81 \cdot 0$ & 0.018 \\
\hline \multicolumn{8}{|l|}{ Price } \\
\hline Good value for money & 115 & $89 \cdot 1$ & 66 & $93 \cdot 0$ & 49 & 84.5 & 0.124 \\
\hline Cheap & 115 & $89 \cdot 1$ & 63 & $88 \cdot 7$ & 52 & 89.7 & 0.867 \\
\hline \multicolumn{8}{|l|}{ Health } \\
\hline Nutritious & 108 & $83 \cdot 7$ & 57 & $80 \cdot 3$ & 51 & $87 \cdot 9$ & 0.242 \\
\hline Keeps me healthy & 106 & $82 \cdot 2$ & 54 & $76 \cdot 1$ & 52 & 89.7 & 0.045 \\
\hline Helps me control weight & 54 & 41.9 & 25 & $35 \cdot 2$ & 29 & $50 \cdot 0$ & 0.090 \\
\hline \multicolumn{8}{|l|}{ Convenience } \\
\hline Easily available & 122 & $94 \cdot 6$ & 67 & 94.4 & 55 & $94 \cdot 8$ & 1.000 \\
\hline Familiar & 53 & $41 \cdot 1$ & 29 & $40 \cdot 8$ & 24 & $41 \cdot 4$ & 0.951 \\
\hline Usually what I eat & 47 & $36 \cdot 4$ & 26 & $36 \cdot 6$ & 21 & $36 \cdot 2$ & 0.961 \\
\hline \multicolumn{8}{|l|}{ How it feels } \\
\hline Makes me feel good & 102 & $79 \cdot 1$ & 56 & $78 \cdot 9$ & 46 & $79 \cdot 3$ & 0.952 \\
\hline Keeps me awake & 91 & $70 \cdot 5$ & 55 & $77 \cdot 5$ & 36 & $62 \cdot 1$ & 0.056 \\
\hline Helps me deal with stress & 37 & $28 \cdot 7$ & 23 & $32 \cdot 4$ & 14 & $24 \cdot 1$ & 0.302 \\
\hline
\end{tabular}

*Multiple answer.

Significant $P$-values are highlighted in bold.

food choice, with statistically significant differences between students and staff $(54.9 \%$ of students $v$. $20.7 \%$ of employees, $P<0.001$ ). Although $24.0 \%$ of the respondents reported using menu passes, more than half (62.0\%) agreed that a loyalty card with which you get discounts on certain foods and drinks in the university would influence their choices. The percentage of students (70.4\%) that supported the use of loyalty cards was significantly higher than that of the staff $(51.7 \%)(P<0.05)$.
Overall satisfaction with foods and drinks sold on campus obtained a score of $6 \cdot 1$ (SD 2.0) out of 10.

\section{Opinions about the food environment}

The most popular opinions suggested about the campus food environment and potential changes were: 'healthier foods for lower cost', 'allergen labelling', 'cheaper foods', 'more discounts for healthy choices', 'fresh fruits', 'freshly 
Table 6 Proposed changes to the campus food environment of OsloMet

\begin{tabular}{|c|c|c|c|c|c|c|c|}
\hline \multirow[b]{2}{*}{ Variables* } & \multicolumn{2}{|c|}{ Total $n 129$} & \multicolumn{2}{|c|}{$\begin{array}{c}\text { Students } \\
n 71\end{array}$} & \multicolumn{2}{|c|}{ Staff $n 58$} & \multirow[b]{2}{*}{$P$} \\
\hline & $n$ & $\% \dagger$ & $n$ & $\% \dagger$ & $n$ & $\% \dagger$ & \\
\hline \multicolumn{8}{|l|}{ Changes to food and variety } \\
\hline Fresh fruit & 96 & 74.4 & 57 & $80 \cdot 3$ & 39 & $67 \cdot 2$ & 0.091 \\
\hline Freshly cooked/prepared foods & 87 & $67 \cdot 4$ & 50 & $70 \cdot 4$ & 37 & $63 \cdot 8$ & 0.424 \\
\hline Sustainable products & 85 & 65.9 & 42 & 59.2 & 43 & $74 \cdot 1$ & 0.074 \\
\hline Variety of food/beverages & 86 & $66 \cdot 7$ & 48 & $67 \cdot 6$ & 38 & 65.5 & 0.802 \\
\hline Ethnic cuisine choices & 67 & 51.9 & 37 & $52 \cdot 1$ & 30 & $51 \cdot 7$ & 0.965 \\
\hline Reduced salt foods & 60 & 46.5 & 31 & 43.7 & 29 & $50 \cdot 0$ & 0.473 \\
\hline Food trucks on campus & 56 & 43.4 & 35 & $49 \cdot 3$ & 21 & $36 \cdot 2$ & 0.136 \\
\hline Special diets choices & 52 & $40 \cdot 3$ & 32 & $45 \cdot 1$ & 20 & $34 . \overline{5}$ & 0.223 \\
\hline Dairy or lactose free foods & 50 & 38.8 & 27 & $38 \cdot 0$ & 23 & 39.7 & 0.850 \\
\hline Gluten-free foods & 45 & 34.9 & 23 & $32 \cdot 4$ & 22 & 37.9 & 0.512 \\
\hline Choices suitable for religious diets & 41 & 31.8 & 22 & $31 \cdot 0$ & 19 & $32 \cdot 8$ & 0.830 \\
\hline Reduced fat foods & 44 & $34 \cdot 1$ & 21 & $29 \cdot 6$ & 23 & 39.7 & 0.230 \\
\hline Low in carbohydrates foods or meals & 38 & 29.5 & 17 & 23.9 & 21 & $36 \cdot 2$ & 0.129 \\
\hline More takeaway food choices & 20 & $15 \cdot 5$ & 15 & $21 \cdot 1$ & 5 & $8 \cdot 6$ & 0.051 \\
\hline Alcoholic beverages & 13 & $10 \cdot 1$ & 9 & $12 \cdot 7$ & 4 & $6 \cdot 9$ & 0.278 \\
\hline Sweets and confectionery & 11 & 8.5 & 10 & $14 \cdot 1$ & 1 & $1 \cdot 7$ & 0.022 \\
\hline Fast-food choices & 7 & 5.4 & 7 & 9.9 & - & & 0.016 \\
\hline \multicolumn{8}{|l|}{ Food labelling } \\
\hline Allergen labelling & 99 & $76 \cdot 7$ & 56 & 78.9 & 43 & $74 \cdot 1$ & 0.527 \\
\hline A mobile application with food and menu information & 78 & 60.5 & 46 & $64 \cdot 8$ & 32 & $55 \cdot 2$ & 0.266 \\
\hline Visual guides for healthier choices & 71 & $55 \cdot 0$ & 42 & $59 \cdot 2$ & 29 & $50 \cdot 0$ & 0.298 \\
\hline Labelling indicating organic produce & 67 & 51.9 & 33 & $46 \cdot 5$ & 34 & $58 \cdot 6$ & 0.170 \\
\hline Detailed nutritional information of foods or dishes & 66 & $51 \cdot 2$ & 33 & 46.5 & 33 & $56 \cdot 9$ & 0.239 \\
\hline Websites information for food and dishes and their nutritional content & 58 & $45 \cdot 0$ & 32 & $45 \cdot 1$ & 26 & 44.8 & 0.978 \\
\hline Healthy symbols or rating systems to guide healthy food choices & 58 & $45 \cdot 0$ & 34 & 47.9 & 24 & 41.4 & 0.460 \\
\hline Calorie labelling on foods & 53 & $41 \cdot 1$ & 27 & $38 \cdot 0$ & 26 & $44 \cdot 8$ & 0.435 \\
\hline \multicolumn{8}{|l|}{ Food costs } \\
\hline Healthier foods for lower cost & 107 & 82.9 & 60 & 84.5 & 47 & $81 \cdot 0$ & 0.602 \\
\hline Cheaper foods & 98 & $76 \cdot 0$ & 61 & $85 \cdot 9$ & 37 & $63 \cdot 8$ & 0.003 \\
\hline More discounts for healthy choices & 97 & $75 \cdot 2$ & 56 & 78.9 & 41 & $70 \cdot 7$ & 0.284 \\
\hline Reward points for sustainable food choices & 85 & 65.9 & 46 & $64 \cdot 8$ & 39 & $67 \cdot 2$ & 0.770 \\
\hline Reward points for healthier food choices & 76 & 58.9 & 42 & $59 \cdot 2$ & 34 & $58 \cdot \overline{6}$ & 0.951 \\
\hline More meal deals & 68 & $52 \cdot 7$ & 44 & $62 \cdot 0$ & 24 & 41.4 & 0.020 \\
\hline Higher quality foods (even for a higher price) & 71 & $55 \cdot 0$ & 31 & 43.7 & 40 & $69 \cdot 0$ & 0.004 \\
\hline \multicolumn{8}{|l|}{ Vending machines } \\
\hline More healthier options available & 78 & 60.5 & 49 & $50 \cdot 0$ & 29 & $69 \cdot 0$ & 0.028 \\
\hline More variety of food and beverages available & 64 & $49 \cdot 6$ & 41 & $57 \cdot 7$ & 23 & 39.7 & 0.041 \\
\hline More hot food and beverages available & 47 & $36 \cdot 4$ & 34 & 47.9 & 13 & $22 \cdot 4$ & 0.003 \\
\hline More food for special diets in vending machines & 38 & 29.5 & 23 & $32 \cdot 4$ & 15 & $25 \cdot 9$ & 0.418 \\
\hline Only healthy options available & 37 & $28 \cdot 7$ & 19 & $26 \cdot 8$ & 18 & $31 \cdot 0$ & 0.593 \\
\hline The removal of vending machines & 22 & $17 \cdot 1$ & 7 & 9.9 & 15 & $25 \cdot 9$ & 0.016 \\
\hline More vending machine & 21 & $16 \cdot 3$ & 15 & $21 \cdot 1$ & 6 & $10 \cdot 3$ & 0.099 \\
\hline \multicolumn{8}{|l|}{ Other changes } \\
\hline Later closing times & 76 & 58.9 & 46 & 64.8 & 30 & $51 \cdot 7$ & 0.134 \\
\hline Freshly made food and beverages available for longer hours & 68 & $52 \cdot 7$ & 41 & $57 \cdot 7$ & 27 & $46 \cdot 6$ & 0.205 \\
\hline Hot food options available for longer hours & 61 & $47 \cdot 3$ & 40 & $56 \cdot 3$ & 21 & $36 \cdot 2$ & 0.023 \\
\hline More cafeterias, restaurants, dining rooms, supermarkets, etc. & 47 & $36 \cdot 4$ & 21 & $29 \cdot 6$ & 26 & $44 . \overline{8}$ & 0.073 \\
\hline Earlier opening times & 30 & $23 \cdot 3$ & 19 & $26 \cdot 8$ & 11 & $19 \cdot 0$ & 0.297 \\
\hline \multicolumn{8}{|l|}{ Facilities provided by the university } \\
\hline Greater capacity to recycle food and beverage packaging & 86 & $66 \cdot 7$ & 45 & 63.4 & 41 & $70 \cdot 7$ & 0.381 \\
\hline Greater capacity to access drinking water & 79 & $61 \cdot 2$ & 54 & $76 \cdot 1$ & 25 & $43 \cdot 1$ & $<0.001$ \\
\hline Greater capacity to heat meals from home in a microwave & 64 & $49 \cdot \overline{6}$ & 42 & $59 \cdot 2$ & 22 & 37.9 & 0.016 \\
\hline
\end{tabular}

*Variables with multiple answer, ordered according to the frequency of response in the total sample (from highest to lowest), within each subsection.

†Percentage of participants who answered that they 'strongly agree' or 'agree' with the proposed changes.

Significant $P$-values are highlighted in bold.

cooked/prepared foods', 'greater capacity to recycle food and beverage packaging', 'sustainable products', 'reward points for sustainable food choices' and 'variety of food/ drinks' (Table 6). The percentages of students in favour of 'more sweets and confectionery', 'cheaper foods', 'higher quality foods (even for a higher price)', 'larger variety of meals', 'more hot food options for longer hours', 'more hot food and drinks in vending machines', 'more variety of food and drinks in vending machines', 'greater capacity to heat meals from home in a microwave' and 'greater capacity to access free filtered drinking water' were higher than those of employees $(P<0.05)$. Staff, on the other hand, most frequently selected the following changes, compared with the students: "more healthy 
options in vending machines' and 'the removal of vending machines'.

\section{Discussion}

The present study aimed to assess the nutritional profile and processing level of commercial foods and drinks offered on food outlets at Pilestredet and Kjeller campus of OsloMet, as well as to analyse on-campus food-purchasing behaviours, preferences and opinions about the food environment by different groups of a university community (students and employees). In summary, in relation to the first of the objectives, almost $40 \%$ of the products were classified as 'unhealthy' according to at least one of the classifications used, and most of them were categorised as 'ultra-processed'. Regarding the second of the aims, cold foods and drinks were the most purchased items. Taste, convenience (availability), cost and nutrition/ health value were the major drivers for food purchase. Moreover, the most popular opinions suggested about the campus food environment and potential changes concerned lower prices, better information on labelling and improved variety of fresh and healthy foods.

Most common commercial foods and drinks offered were sweet snacks and sugar-sweetened carbonated drinks, which were characterised by high SFA and sugar content, respectively. These results are similar to those from previous studies conducted at universities ${ }^{(34-36)}$ that suggest that the offer of healthy options is limited, which favours the choice of high-energy, low-nutrient products. The frequent consumption of this type of product has been associated with a higher intake of fat and added sugars ${ }^{(37)}$, which can result in poorer diet quality ${ }^{(38)}$.

Consistent with other research conducted in university environments ${ }^{(34-36,39)}$, it was found that four out of ten of the foods and drinks offered were 'unhealthy' according to the AECOSAN's criteria, the UK model and MFU criteria. The models with the highest agreement were UK NPM and AECOSAN, while those with the worst agreement were AECOSAN and MFU. The differences in the results obtained from the three NPM, in the present study, could be related to discrepancies in constructs and scoring criteria for the models used. In fact, MFU's criteria are more restrictive in terms of sugar and sweetener content, especially in drinks, than AECOSAN's criteria. Therefore, the percentage of products, in particular, those with added sugars and/or sweeteners, classified as 'unhealthy' was higher with MFU's than with AECOSAN's criteria.

On the other hand, most of the products offered had a high level of processing. In the literature, the proportion of unhealthy items sold on campus has been highly variable, probably because the criteria used were different ${ }^{(34-36)}$. Anyway, the processing level classification used in the present study showed a low level of agreement with the NPM. This result is probably due to the fact that although ultra-processed foods usually are characterised by a high content of sugar, salt and/or fats, these contents do not always exceed the limits of the NPM. As other authors have pointed out, ultra-processed foods had in general a worse nutrient profile than less processed foods ${ }^{(40)}$.

In the survey on food purchasing and food choice behaviours, it was observed that a majority of the participants purchased some foods or beverage items on campus and for most, it was on equal or greater than half the occasions of attending university. These purchases were usually made in the canteen of one of the campuses and cafeteria and the eating/drink occasions were mostly at lunch and between meals. Approximately one in three participants followed a special diet, especially a vegetarian or vegan diet, followed by weight-management diets. This result was in agreement with previous research ${ }^{(11)}$ which attributed the exclusion of certain food groups (especially meat) to health concerns or other beliefs ${ }^{(21)}$ and the obesity prevalence $^{(41)}$.

Students and staff tended to purchase cold foods (especially salads, sandwiches or wraps) and drinks (coffee and hot chocolate) mostly, followed by hot foods and snacks. Students purchased more cold sandwiches or wraps, fresh fruit, other snacks and drinks in general than staff, which is in line with that a higher number of eating/drinking occasions were registered in this study for students than employees. The results related to the consumption of drinks in the total sample, as well as those related to the differences between students and staff in the consumption of hot sandwiches, wraps, pizzas and burgers, were similar to those registered at a university in New Zealand ${ }^{(42)}$. However, students of the present study consumed fresh fruit more frequently than did those of New Zealand ${ }^{(42)}$.

Consistent with previous studies ${ }^{(43-45)}$, the top determinants of food-purchasing behaviours were taste, convenience (availability), cost and nutrition/health value, with no difference between students and staff, with the exception of sensory appeal (such as smell and look) and health considerations. These last factors were more important for staff than for students on the types of foods selected for consumption.

Although no differences were found between groups regarding cost factor, it should be noted that a higher percentage of students than employees considered that ' $2 \times 1$ offers' or 'offers of large portions of food prepared at reduced prices' influence their food choice. This result could be related to differences by age ${ }^{(46)}$ and socioeconomic status $^{(47)}$. Thus, future interventions addressing on-campus food environments should focus on ensuring the ready availability of tasty and nutritious foods to purchase at a low cost. Moreover, given that the nutrition/ health value of foods was also perceived to be of importance, the potential for nutrition labelling or nutrition/health-related claims could be an interesting strategy to promote the consumption of healthier foods in this population. 
Our findings are consistent with previous studies that suggested that overall satisfaction with campus food was moderated by variety, quality, convenience and fair pricing ${ }^{(48,49)}$. Three out of five most popular proposed changes to the food environment pertained to cost. The majority of respondents wanted to see healthier food at a lower cost and less expensive food in general. Given the evidence that food price influences food purchasing ${ }^{(50)}$, several pricing interventions have been conducted, with findings suggesting that price discounts on targeted healthier foods can increase their purchase ${ }^{(49,51)}$.

The second most popular change to the campus food environment was an improvement in allergen information on labelling followed by an increase in the supply of fresh and healthy foods. As other authors have previously pointed out, increasing labelled and fresh and healthy options on campus should be effective in improving the food environment ${ }^{(49)}$. Finally, three out of ten most popular proposed changes to the food environment pertained to sustainability, specifically, 'greater capacity to recycle food and beverage packaging', 'sustainable products', and 'reward points for sustainable food choices'. This result agreed with the findings of other authors ${ }^{(11,49)}$. In this line, institutional food-service guidelines approaching health and sustainability from an ecologic perspective have been developed and successfully implemented at universities $^{(52,53)}$

In view of the results of the present study and those of intervention studies carried out by other researchers, we consider that lowering price, improving the allergen information on labelling and increasing the variety of fresh and healthy foods on campus should improve satisfaction and be effective in encouraging a more healthy consumption. However, since fresh and healthy foods are usually associated with a higher cost ${ }^{(35)}$, the economic feasibility of the price discounts, as well as possible strategies to reduce food-purchasing costs should be investigated. As other authors have pointed out, facilitating accessibility to healthy foods increases their consumption ${ }^{(54,55)}$. In previous studies in which the effect of decreasing the price of healthy foods ${ }^{(56)}$ and/or increasing the price of unhealthy items on consumption ${ }^{(57,58)}$ has been evaluated, the efficacy of both strategies has been shown. Although putting these strategies into practice in a university with multiple and small campuses, as for OsloMet, could be difficult, they would probably be more effective if combined with increased availability of healthy foods on campus. A greater presence of affordable healthy foods would likely promote a significant effect on purchasing and consumption.

Even if the present study was successful in generating a representative sample, some limitations of selection bias should be noted. First, the COVID-19 pandemic could have influenced the survey participation rate, since the campus closed down just as the survey started. In any case, the data recorded corresponded to before closing. A post hoc power calculation was performed based on the available sample size, which resulted in a power of $98 \%$ for the observed percentage of participants who bought food or beverages on campus compared to the percentage reported by Roy et al. ${ }^{(42)}$, based on an $\alpha$ error rate of 0.05 using a two-tailed test.

Second, the offer of commercial products on food outlets has been analysed from the perspectives of health; however, the offer of home-made products has not been studied. We plan to assess the complete offer in the future to make broader conclusions about the present study. Third, in the survey sample, there were more female respondents than male, and as previous studies have reported, women are more health conscious concerning food ${ }^{(59)}$. Moreover, the percentage of women and respondents from Health Sciences area was higher in the study sample than in the total population ${ }^{(22)}$, which could have implications in the conclusions of this work.

Fourth, the survey results may have been biased towards the perspective of the students' group given their slight overrepresentation. In any case, convenience sampling is more likely to attract those more interested in university food services. The decision to participate or not may have been influenced by several factors, including social, educational and health conditions, which may influence the answers. Thus, the results may not be generalisable to the wider population of this university community or other tertiary institutions.

Another limitation of the survey was related to the design of the questionnaire used in the survey. Participants could not rank their preferences from highest to lowest. To solve this problem, in future researches a ranking system will be used to analyse the relative importance of each preference.

Despite these limitations and considering the results obtained, we can conclude that: (i) a high proportion of the commercial products offered in food outlets are in the 'unhealthy' category and most have a high level of processing and (ii) according to the opinions suggested about campus food environment and potential changes, to increase satisfaction with campus food by the university community, future promotion should target viable pricemanipulation directives, improving the allergen information on labelling and increasing the variety of fresh and healthy foods. These changes in the food supply, of course taking into account taste preferences, could positively affect food consumption habits in this population and decrease the risk of chronic disease in the long term. These findings are relevant for planning interventions to improve the food environment in this and similar tertiary education settings.

\section{Acknowledgements}

Acknowledgements: The authors want to particularly acknowledge the participants who enrolled in this study 
for their participation and the Foundation for Student Life in Oslo and Akershus (Studentsamskipnaden i Oslo og Akershus, SiO) for its collaboration. Financial support: This project was supported by the UPV/EHU (EHU12/24), the Vice Rector for Innovation, Social Outreach and Cultural Activities of the UPV/EHU, funding by the contract-program formalised with the Basque Government (code of the Campus Bizia Lab project: 19ARRO) and by the Department of Nursing and Health Promotion of the OsloMet. The authors also acknowledge the support provided by the Erasmus Doctoral Program (2019-2020) for the fellowship grant. Open Access funding provided by the UPV/EHU. Conflict of interest: There are no conflicts of interest. Authorship: N.M.-P. and L.E.T. acquired the data; N.M.-P. and N.C.-D. analysed the data; N.M.-P. and M.A.-I. interpreted the results and drafted the manuscript. N.M.-P., L.E.T. and M.A.-I. contributed to the conception and design of the research. All authors revised the paper and approved the final version of the manuscript. Ethics of human subject participation: This study was conducted according to the guidelines laid down in the Declaration of Helsinki, and all procedures involving research study participants were approved by the Committee of Ethics in Research with Human Beings (CEISH) of the University of the Basque Country. Written informed consent was obtained from all subjects.

\section{Supplementary material}

For supplementary material accompanying this paper visit https://doi.org/10.1017/S136898002100272X

\section{References}

1. Turner C, Kadiyala S, Aggarwal A et al. (2017) Concepts and methods for food environment research in low and middle income countries. In Innovative Methods and Metrics for Agriculture and Nutrition Actions (IMMANA) Programme. London: Agriculture, Nutrition and Health Academy Food Environments Working Group (ANH-FEWG). https:// www.researchgate.net/publication/317035530_Concepts_and_ methods_for_food_environment_research_in_low_and_middle_ income_countries (accessed June 2020).

2. Fuentes Pacheco A, Carrillo Balam G, Archibald D et al. (2018) Exploring the relationship between local food environments and obesity in UK, Ireland, Australia and New Zealand: a systematic review protocol. BMJ Open $\mathbf{8}$, e018701.

3. Sharkey JR, Johnson CM \& Dean WR (2010) Food access and perceptions of the community and household food environment as correlates of fruit and vegetable intake among rural seniors. BMC Geriatr 10, 32.

4. Gamba RJ, Schuchter J, Rutt C et al. (2015) Measuring the food environment and its effects on obesity in the United States: a systematic review of methods and results. J Community Health 40, 464-475.

5. Chen SE, Florax RJ \& Snyder SD (2013) Obesity and fast food in urban markets: a new approach using geo-referenced micro data. Health Econ 22, 835-856.
6. Den Braver N, Lakerveld J, Rutters F et al. (2018) Built environmental characteristics and diabetes: a systematic review and meta-analysis. BMC Med 16, 12.

7. Wilkins E, Radley D, Morris M et al. (2019) A systematic review employing the GeoFERN framework to examine methods, reporting quality and associations between the retail food environment and obesity. Health Place 57, 186-199.

8. He M, Tucker P, Gilliland J et al. (2012) The influence of local food environments on adolescents' food purchasing behaviors. Int J Environ Res Public Health 9, 1458-1471.

9. Story M, Kaphingst KM, Robinson-O'Brien R et al. (2008) Creating healthy food and eating environments: policy and environmental approaches. Annu Rev Public Health 29, 253-272.

10. Deliens T, Clarys P, De Bourdeaudhuij I et al. (2014) Determinants of eating behaviour in university students: a qualitative study using focus group discussion. $B M C$ Public Health 14, 53.

11. Tam R, Yassa B, Parker H et al. (2017) University students' on-campus food purchasing behaviors, preferences, and opinions on food availability. Nutrition 37, 7-13.

12. Glanz K, Sallis JF, Saelens BE et al. (2005) Healthy nutrition environments: concepts and measures. Am J Health Promot 19, 330-333.

13. Kelly NR, Mazzeo SE \& Bean MK (2013) Systematic review of dietary interventions with college students: directions for future research and practice. J Nutr Educ Behav 45, 304-313.

14. Vadeboncoeur C, Foster C \& Townsend N (2016) Freshman 15 in England: a longitudinal evaluation of first year university student's weight change. BMC Obes $\mathbf{3}, 45$.

15. Baum CL 2nd (2017) The effects of college on weight: examining the "Freshman 15" myth and other effects of college over the life cycle. Demography 54, 311-336.

16. Vadeboncoeur C, Townsend N \& Foster CH (2015) A metaanalysis of weight gain in first year university students: is freshman 15 a myth? BMC Obes $\mathbf{2}, 22$.

17. Gores SE (2008) Addressing nutritional issues in the collegeaged client: strategies for the nurse practitioner. J Am Acad Nurs Pract 20, 5-10.

18. Jiang Y, Wang J, Wu S et al. (2019) Association between takeout food consumption and obesity among Chinese university students: a cross-sectional study. Int J Environ Res Public Health 16, 1071.

19. Al Sabbah H (2020) Prevalence of overweight/obesity, anaemia and their associations among female university students in Dubai, United Arab Emirates: a cross-sectional study. J Nutr Sci 9, e26.

20. Freedman MR \& Rubinstein RJ (2010) Obesity and food choices among faculty and staff at a large urban university. J Am Coll Health 59, 205-210.

21. Jun J, Arendt SW \& Kang J (2016) Understanding customers' healthful food selection at restaurants: roles of attitude, gender, and past experience. J Food Serv Bus Res 19, 197-212.

22. Oslo Metropolitan University (2019) Årsrapport 2019 (Annual report 2019). https://ansatt.oslomet.no/documents/ 585743/54495365/\%C3\%85rsrapport+2019/ (accessed April 2020).

23. Norwegian Directorate of Health \& Norwegian Food Safety Authority (n.d.) Kostholdsplanleggeren (Diet planner). https://www.kostholdsplanleggeren.no/ (accessed June 2020).

24. Agencia Española de Consumo, Seguridad Alimentaria y Nutrición (AECOSAN) (2010) Documento de Consenso sobre la Alimentación en los Centros Educativos (Consensus Document on Food in Educational Centers). Madrid: Ministerio de Educación, Ministerio de Sanidad, Política Social e Igualdad, Agencia Española de Seguridad Alimentaria y Nutrición. 
25. Lobstein T \& Davies S (2009) Defining and labelling 'healthy' and 'unhealthy' food. Public Health Nutr 12, 331-340.

26. Matbransjens Fagligle Utvalg (MFU) (2013) Food and Drink Industry Professional Practices Committee Norway. https:// nye.mfu.as/complete-product-list/ (accessed June 2020).

27. Department of Health (2011) Nutrient Profiling Technical Guidance. London: Department of Health.

28. Labonté ME, Poon T, Gladanac B et al. (2018) Nutrient profile models with applications in government-led nutrition policies aimed at health promotion and noncommunicable disease prevention: a systematic review. Adv Nutr 9, 741-788.

29. Monteiro CA, Cannon G, Levy R et al. (2016) Food classification. Public health NOVA. The star shines bright. World Nutr 7, 28-38.

30. Organización Panamericana de la Salud (OPS) \& Organización Mundial de la Salud (OMS) (2005) Alimentos y Bebidas Ultraprocesados en América Latina: Tendencias, Efecto sobre la Obesidad e Implicaciones para las Políticas Públicas (Ultra-Processed Food and Drink Products in Latin America: Trends, Impact on Obesity and Policy Implications). Washington, DC: Departamento de Enfermedades no Transmisibles y Salud Mental.

31. Popping R (2015) Analyzing open-ended questions by means of text analysis procedures. Bull Methodol Sociol 128, 23-39.

32. Hervada X, Santiago MI, Vázquez E et al. (2006) Epidat v. 3.1: Análisis Epidemiológico de Datos Tabulados (Epidat v. 3.1: Epidemiological Analysis of Tabulated Data). A Coruña: Xunta de Galicia.

33. Landis JR \& Koch GG (1977) The measurement of observer agreement for categorical data. Biometrics 33, 159-174.

34. Horacek TM, Erdman MB, Reznar MM et al. (2013) Evaluation of the food store environment on and near the campus of 15 postsecondary institutions. Am J Health Promot 27, e81-e90.

35. Roy R, Hebden L, Kelly B et al. (2016) Description, measurement and evaluation of tertiary-education food environments. Br J Nutr 115, 1598-1606.

36. Horacek TM, Erdman MB, Byrd-Bredbenner C et al. (2013) Assessment of the dining environment on and near the campuses of fifteen post-secondary institutions. Public Health Nutr 16, 1186-1196.

37. Pelletier JE \& Laska MN (2013) Campus food and beverage purchases are associated with indicators of diet quality in college students living off campus. Am J Health Promot 28, 80-87.

38. Roy R, Rangan A, Hebden L et al. (2017) Dietary contribution of foods and beverages sold within a university campus and its effect on diet quality of young adults. Nutrition $\mathbf{3 4}$, 118-123.

39. Byrd-Bredbenner C, Johnson M, Quick VM et al. (2012) Sweet and salty. An assessment of the snacks and beverages sold in vending machines in US post-secondary institution campuses. Appetite 58, 1143-1151.

40. Luiten CM, Steenhuis IH, Eyles H et al. (2016) Ultraprocessed foods have the worst nutrient profile, yet they are the most available packaged products in a sample of New Zealand supermarkets. Public Health Nutr 19, 530-538.

41. Kjaer IG, Kolle E, Hansen BH et al. (2015) Obesity prevalence in Norwegian adults assessed by body mass index, waist circumference and fat mass percentage. Clin Obes 5, 211-218.
42. Roy R, Soo D, Conroy D et al. (2019) Exploring university food environment and on-campus food purchasing behaviors, preferences, and opinions. J Nutr Educ Behav 51, 865-875.

43. Hebden L, Chan HN, Louie JC et al. (2015) You are what you choose to eat: factors influencing young adults' food selection behaviour. J Hum Nutr Diet 28, 401-408.

44. Januszewska R, Pieniak Z \& Verbeke W (2011) Food choice questionnaire revisited in four countries. Does it still measure the same? Appetite 57, 94-98.

45. Milošević J, Žeželj I, Gorton M et al. (2012) Understanding the motives for food choice in Western Balkan Countries. Appetite 58, 205-214.

46. Muhammad A, D'Souza A, Meade B et al. (2017) How income and food prices influence global dietary intakes by age and sex: evidence from 164 countries. BMJ Glob Health 2, e000184.

47. Darmon N \& Drewnowski A (2015) Contribution of food prices and diet cost to socioeconomic disparities in diet quality and health: a systematic review and analysis. Nutr Rev 73, 643-660.

48. Liang X \& Zhang S (2009) Investigation of customer satisfaction in student food service an example of student cafeteria in NHH. Int I Qual Serv Sci 1, 113-124.

49. Roy R, Kelly B, Rangan A et al. (2015) Food environment interventions to improve the dietary behavior of young adults in tertiary education settings: a systematic literature review. J Acad Nutr Diet 115, 1647.e1-1681.e1.

50. Epstein LH, Jankowiak N, Nederkoorn C et al. (2012) Experimental research on the relation between food price changes and food-purchasing patterns: a targeted review. Am J Clin Nutr 95, 789-809.

51. Phipps EJ, Braitman LE, Stites SD et al. (2015) Impact of a rewards-based incentive program on promoting fruit and vegetable purchases. Am J Public Health 105, 166-172.

52. Emory University of Sustainable Initiatives (2016) Food \& Dining. Supporting a healthy, local food system. http:// sustainability.emory.edu/page/1008/Sustainable-Food (accessed September 2020).

53. Yale University Guides (2011) Sustainable Procurement Standards Guide (3201GD.02). https://your.yale.edu/sites/ default/files/3201gd.02.pdf (accessed September 2020).

54. Downs JS, Loewenstein G \& Wisdom J (2009) Strategies for promoting healthier food choices. Am Econ Rev 99, 159-164.

55. Lachat CK, Verstraeten R, De Meulenaer B et al. (2009) Availability of free fruits and vegetables at canteen lunch improves lunch and daily nutritional profiles: a randomised controlled trial. Br J Nutr 102, 1030-1037.

56. Thow AM, Jan S, Leeder S et al. (2010) The effect of fiscal policy on diet, obesity and chronic disease: a systematic review. Bull World Health Organ 88, 609-614.

57. An R (2013) Effectiveness of subsidies in promoting healthy food purchases and consumption: a review of field experiments. Public Health Nutr 16, 1215-1228.

58. Alagiyawanna A, Townsend N, Mytton O et al. (2015) Studying the consumption and health outcomes of fiscal interventions (taxes and subsidies) on food and beverages in countries of different income classifications; a systematic review. BMC Public Health 15, 887.

59. Levi A, Chan KK \& Pence D (2006) Real men do not read labels: the effects of masculinity and involvement on college students' food decisions. J Am Coll Health 55, 91-98. 